\title{
The neuroprotective potential of flavonoids: a multiplicity of effects
}

\author{
David Vauzour · Katerina Vafeiadou • \\ Ana Rodriguez-Mateos · Catarina Rendeiro · \\ Jeremy P. E. Spencer
}

Published online: 21 October 2008

(C) Springer-Verlag 2008

\begin{abstract}
Flavonoids exert a multiplicity of neuroprotective actions within the brain, including a potential to protect neurons against injury induced by neurotoxins, an ability to suppress neuroinflammation, and the potential to promote memory, learning and cognitive function. These effects appear to be underpinned by two common processes. Firstly, they interact with critical protein and lipid kinase signalling cascades in the brain leading to an inhibition of apoptosis triggered by neurotoxic species and to a promotion of neuronal survival and synaptic plasticity. Secondly, they induce beneficial effects on the vascular system leading to changes in cerebrovascular blood flow capable of causing angiogenesis, neurogenesis and changes in neuronal morphology. Through these mechanisms, the consumption of flavonoid-rich foods throughout life holds the potential to limit neurodegeneration and to prevent or reverse age-dependent loses in cognitive performance. The intense interest in the development of drugs capable of enhancing brain function means that flavonoids may represent important precursor molecules in the quest to develop of a new generation of brain enhancing drugs.
\end{abstract}

D. Vauzour - K. Vafeiadou - A. Rodriguez-Mateos ·

C. Rendeiro - J. P. E. Spencer

Molecular Nutrition Group, School of Chemistry,

Food and Pharmacy, University of Reading,

Reading RG2 6AP, UK

D. Vauzour

e-mail: d.vauzour@reading.ac.uk

J. P. E. Spencer ( $\square)$

School of Food Biosciences, University of Reading, PO Box 226, Whiteknights, Reading RG6 6AP, UK e-mail: j.p.e.spencer@ reading.ac.uk
Keywords Flavonoid - Brain - Neuroprotection · Neuroinflammation $\cdot$ Memory $\cdot$ Cognitive function

\section{Introduction}

Recently, there has been intense interest in the potential of flavonoids to modulate neuronal function and prevent against age-related neurodegeneration. The use of flavonoid-rich plant or food extracts in humans and animal dietary supplementation studies have shown improvements in cognition function possibly by protecting vulnerable neurons, enhancing existing neuronal function or by stimulating neuronal regeneration [134]. Their neuroprotective potential has been shown in both oxidative stress [41] and A $\beta$-induced neuronal death models [65]. Evidence also exists for the beneficial and neuromodulatory effects of flavonoid-rich ginkgo biloba extracts, particularly in connection with age-related dementias and Alzheimer's disease [7]. Furthermore, individual flavonoids such as the citrus flavanone tangeretin, has been observed to maintain nigro-striatal integrity and functionality following lesioning with 6hydroxydopamine, suggesting that it may serve as a potential neuroprotective agent against the underlying pathology associated with Parkinson's disease [24]. In addition, flavonoids may also exert beneficial effects on memory and may prevent cognitive losses associated with ageing and even reverse certain age-related declines $[45,46]$. This review will highlight the neuroprotective mechanisms of flavonoids and other polyphenols, in particular their ability interact with neuronal signalling pathways [91, 97] and their potential to inhibit neuroinflammatory processes in the brain [17, 48]. 


\section{Flavonoid: sources and structure}

Flavonoids are major constituents of fruit, vegetables and beverages, such as wine, tea, cocoa and fruit juices. Most commonly, flavonoids share a common structure consisting of two aromatic rings (A and $\mathrm{B}$ ), which are bound together by three carbon atoms, forming an oxygenated heterocycle (ring C) (Fig. 1). Based on variations in the saturation of the basic flavan ring system, their alkylation and/or glycosylation and the hydroxylation pattern of the molecules, flavonoids may be divided into seven subclasses: flavonols, flavones, flavanones, flavanonols, flavanols, anthocyanidins, and isoflavones (reviewed by Manach et al. [67]).

The flavanols, sometimes referred to as flavan-3-ols, are found predominantly in green and black teas, red wine and chocolate. Variations in their structures lie in the hydroxylation pattern of the $\mathrm{B}$ ring and the presence of gallic acid in position 3. The lack of a double bond at the 2-3 position and the presence of a 3-hydroxyl group on the C-ring create two centres of asymmetry. Typical dietary flavanols include catechin, epicatechin, epigallocatechin (EGC) and epigallocatechin gallate (EGCG) (Fig. 1). Flavanols exist also as oligomers or polymers, referred to as condensed tannins or proanthocyanidins, which are found in high concentration in cocoa, tea, red wine and fruits such as apples, grapes and strawberries. These differ in nature based on their constitutive units (e.g. catechins and epicatechin), their sequence and the position of interflavanic linkages. The sources of anthocyanins such as pelargonidin, cyanidin and malvidin include red wine and berry fruits such as blueberries, blackberries cherries and strawberries. These compounds exist as glycosides in plants, are water-soluble and appear red or blue according to $\mathrm{pH}$. Individual anthocyanins arise from the variation in number and arrangement of the hydroxyl and methoxy groups around the three rings (Fig. 1). Flavones such as apigenin, luteolin are found in parsley, chives, artichoke and celery. Hydroxylation on position 3 of the flavone structure gives rise to the 3-hydroxyflavones also known as the flavonols (e.g. kaempferol, quercetin), which are found in onions, leeks, broccoli (Fig. 1). The diversity of these compounds stems from the varying positions of phenolic - $\mathrm{OH}$ groups around the three rings. Dietary flavanones include naringenin, hesperetin and taxifolin and are found predominantly in citrus fruit and tomatoes. Hydroxylation of flavanones in position 3 of C-ring gives rise to the flavanonols (Fig. 1). Finally, isoflavones such as daidzein and genistein are a subclass of the flavonoid family found in soy and soy products. They have a large structural variability and more than 600 isoflavones have been identified to date and are classified according to oxidation level of the central pyran ring (Fig. 1).

\section{Absorption, metabolism and distribution of flavonoids}

Although flavonoids have been identified as powerful antioxidants in vitro [84-86], their ability to act as antioxidants in vivo is limited by the extensive biotransformation and conjugation which occurs during their absorption from the gastrointestinal (GI) tract, in the liver and finally in cells (reviewed in [103, 107]). In the small intestine and liver, dietary flavonoids (and other polyphenols) are substrates for phase I (hydrolysing and oxidizing) and phase II (conjugating and detoxifying), meaning that they are de-glucosylated and metabolised into glucuronides, sulphates and $O$-methylated derivatives [99, 103, 104]. Further metabolism occurs in the colon, where the enzymes of the gut microflora induce the breakdown of flavonoids to simple phenolics acids that may then undergo absorption and further metabolized in the liver [88]. Furthermore, flavonoids may undergo at least three types of intracellular metabolism: (1) Oxidative metabolism, (2) P450-related metabolism and (3) Conjugation with thiols, particularly GSH [100]. Circulating metabolites of flavonoids, such as glucuronides, sulphates and conjugated $O$-methylated forms, or intracellular metabolites like flavonoid-GSH adducts, have significantly reduced antioxidant potential relative to the forms found in plants [102]. Indeed, studies have indicated that although such conjugates and metabolites may participate antioxidant reactions and may scavenge reactive oxygen and nitrogen species in the circulation, their effectiveness to do so is reduced compared to their parent aglycones [22, 70, 94, 117, 132].

In order for flavonoids to access the brain, they must first cross the blood brain barrier (BBB), which controls entry of xenobiotics into the brain [2]. Flavanones such as hesperetin, naringenin and their in vivo metabolites, along with some dietary anthocyanins, cyanidin-3-rutinoside and pelargonidin-3-glucoside, have been shown to traverse the BBB in relevant in vitro and in situ models [135]. Their degree of BBB penetration is dependent on compound lipophilicity [133], meaning that less polar $O$-methylated metabolites may be capable to greater brain uptake than the more polar flavonoid glucuronides. However, evidence exists to suggest that certain drug glucuronides may cross the BBB [1] and exert pharmacological effects [52, 112], suggesting that there may be a specific uptake mechanism for glucuronides in vivo. Their brain entry may also depend on their interactions with specific efflux transporters expressed in the BBB, such as P-glycoprotein [63] which appears to be responsible for the differences between naringenin and quercetin flux into the brain in situ [135]. In animals, flavanones have been found to enter the brain following their intravenous administration [79], whilst epigallocatechin gallate [115], epicatechin [3] and anthocyanins $[26,116]$ are found in the brain after their oral 


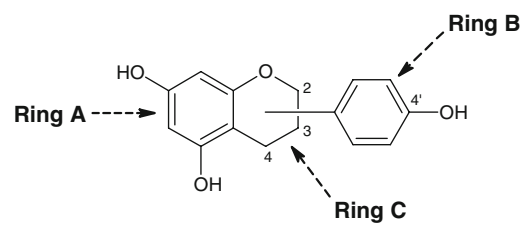<smiles>[R6]c1cc(C2Oc3cc(O)cc(O)c3CC2Br)cc(O)c1O</smiles>

\begin{tabular}{lcc}
\hline Flavanols & & \\
& $\boldsymbol{R}_{\mathbf{1}}$ & $\boldsymbol{R}_{\mathbf{4}}$ \\
Catechin & $\mathrm{OH}$ & $\mathrm{H}$ \\
Epicatechin & $\mathrm{OH}$ & $\mathrm{H}$ \\
EGC & $\mathrm{OH}$ & $\mathrm{OH}$ \\
ECG & gallate & $\mathrm{H}$ \\
EGCG & gallate & $\mathrm{OH}$ \\
& & \\
\hline
\end{tabular}<smiles>[R6]c1cc(C2Oc3cc(O)cc(O)c3C(=O)C2Br)ccc1Br</smiles>

\begin{tabular}{cccc}
\hline Flavanones & & & \\
\hline & $\mathbf{R}_{\mathbf{1}}$ & $\mathbf{R}_{\mathbf{2}}$ & $\mathbf{R}_{\mathbf{3}}$ \\
Naringenin & $\mathrm{H}$ & $\mathrm{H}$ & $\mathrm{OH}$ \\
Hesperetin & $\mathrm{H}$ & $\mathrm{OCH}_{3}$ & $\mathrm{H}$ \\
& & & \\
\hline Flavanonols & & & \\
\hline \multirow{2}{*}{ Taxifolin } & $\mathrm{OH}$ & $\mathrm{OH}$ & $\mathrm{OH}$ \\
Astilbin & O-rhamnosyl & $\mathrm{OH}$ & $\mathrm{OH}$ \\
Engeletin & O-rhamnosyl & $\mathrm{H}$ & $\mathrm{OH}$ \\
& & & \\
\hline
\end{tabular}

Fig. 1 The structures of the main classes of flavonoids. The major differences between the individual groups reside in the hydroxylation pattern of the ring-structure, the degree of saturation of the C-ring and the substitution of in the 3-position: a general structure of flavonoids,<smiles>[R8]c1cc(-c2oc3cc(O)cc(O)c3c(=O)c2Br)cc(Br)c1O</smiles>

\begin{tabular}{llcc}
\hline Flavonols & & & \\
\hline & $\boldsymbol{R}_{\mathbf{1}}$ & $\boldsymbol{R}_{\mathbf{2}}$ & $\boldsymbol{R}_{\mathbf{3}}$ \\
Kaempferol & $\mathrm{OH}$ & $\mathrm{H}$ & $\mathrm{H}$ \\
Quercetin & $\mathrm{OH}$ & $\mathrm{OH}$ & $\mathrm{H}$ \\
$\begin{array}{l}\text { Myricetin } \\
\text { Isorhamnetin }\end{array}$ & $\mathrm{OH}$ & $\mathrm{OH}$ & $\mathrm{OH}$ \\
& $\mathrm{OH}$ & $\mathrm{OCH}_{3}$ & $\mathrm{H}$ \\
\hline Flavones & & & \\
\hline Luteolin & $\mathrm{H}$ & $\mathrm{OH}$ & $\mathrm{H}$ \\
Apigenin & $\mathrm{H}$ & $\mathrm{H}$ & $\mathrm{H}$ \\
& & & \\
\hline
\end{tabular}

$\mathrm{HO}$<smiles></smiles>

\begin{tabular}{ccc}
\hline Anthocyanidins & & \\
\hline & $\mathbf{R}_{1}$ & $\mathbf{R}_{\mathbf{2}}$ \\
Pelargonidin & $\mathrm{H}$ & $\mathrm{H}$ \\
Cyanidin & $\mathrm{OH}$ & $\mathrm{H}$ \\
Delphinidin & $\mathrm{OH}$ & $\mathrm{OH}$ \\
Paeonidin & $\mathrm{OCH}_{3}$ & $\mathrm{H}$ \\
Petunidin & $\mathrm{OCH}_{3}$ & $\mathrm{OH}$ \\
Malvidin & $\mathrm{OCH}_{3}$ & $\mathrm{OCH}_{3}$ \\
& & \\
\hline
\end{tabular}

$\mathrm{HO}$<smiles>[R]c1ccc(C2COc3cccc([R])c3C2=O)cc1</smiles>

\begin{tabular}{lcc}
\hline Isoflavones & & \\
& $\mathbf{R}_{1}$ & $\mathbf{R}_{\mathbf{2}}$ \\
Genistein & $\mathrm{OH}$ & $\mathrm{OH}$ \\
Daidzein & $\mathrm{OH}$ & $\mathrm{H}$ \\
& & \\
\hline
\end{tabular}

b structure of flavonols and flavones, c structure of flavanols, also referred as flavan-3-ols, $\mathbf{d}$ structure of anthocyanidins, e structure of flavanones and flavanonols and $\mathbf{f}$ structure of isoflavones 
administration. Furthermore, several anthocyanins have been identified in different regions of the rat [78] and pig brains [47] of blueberry fed animals, with 11 intact anthocyanins found in the cortex and cerebellum. Studies have indicated that the accumulation of flavonoids in the brain is not dependent on the brain region, with levels of anthocyanins reaching $0.45 \pm 0.12 \mathrm{nmol} / \mathrm{g}$ in the hippocampus and $0.46 \pm 0.11 \mathrm{nmol} / \mathrm{g}$ in the cortex following intervention with a $2 \% \mathrm{w} / \mathrm{w}$ blueberry diet for 12 weeks [129]. Flavanols have been shown to accumulate at significantly higher levels (Hippocampus: $2.65 \pm 0.17 \mathrm{nmol} /$ $\mathrm{g}$ tissue; cortex levels were $2.54 \pm 0.18$ ), following the same dietary intervention. These results indicate that flavonoids traverse the BBB and are able to localize in the brain, suggesting that they are candidates for direct neuroprotective and neuromodulatory actions.

\section{Protection against neuronal injury induced by neurotoxins}

Neurodegeneration in Parkinson's, Alzheimer's, and other neurodegenerative diseases appears to be triggered by multi-factorial events including neuroinflammation, glutamatergic excitotoxicity, increases in iron and/or depletion of endogenous antioxidants $[6,44,113]$. There is a growing body of evidence to suggest that flavonoids may be able to counteract the neuronal injury underlying these disorders [68, 98, 105]. For example, a Ginkgo biloba extract has been shown to protect hippocampal neurons from nitric oxide- and beta-amyloid-induced neurotoxicity [65] and studies have demonstrated that the consumption of green tea may have beneficial effect in reducing the risk of Parkinson's disease [16]. In agreement with the latter study, tea extracts and (-)-epigallocatechin-3-gallate (EGCG) have also been shown to attenuate 6-hydroxydopamineinduced toxicity [61], to protect against hippocampal injury during transient global ischemia [56] and to prevent nigral damage induced by MPTP [60].

The death of nigral neurons in Parkinson's disease is thought to involve the formation of the endogenous neurotoxin, 5-S-cysteinyl-dopamine [108, 109]. Recent investigations have shown that 5-S-cysteinyl-catecholamine conjugates possess strong neurotoxicity and initiate a sustained increase in intracellular reactive oxygen species (ROS) in neurons leading to DNA oxidation, caspase-3
Fig. 2 Involvement of neuroinflammation, endogenous neurotoxins and oxidative stress in dopaminergic

neurodegeneration. Structures of the 5-S-cysteinyl-dopamine (5-S-Cys-DA) and the dihydrobenzothiazine-1 (DHBT-1) are shown

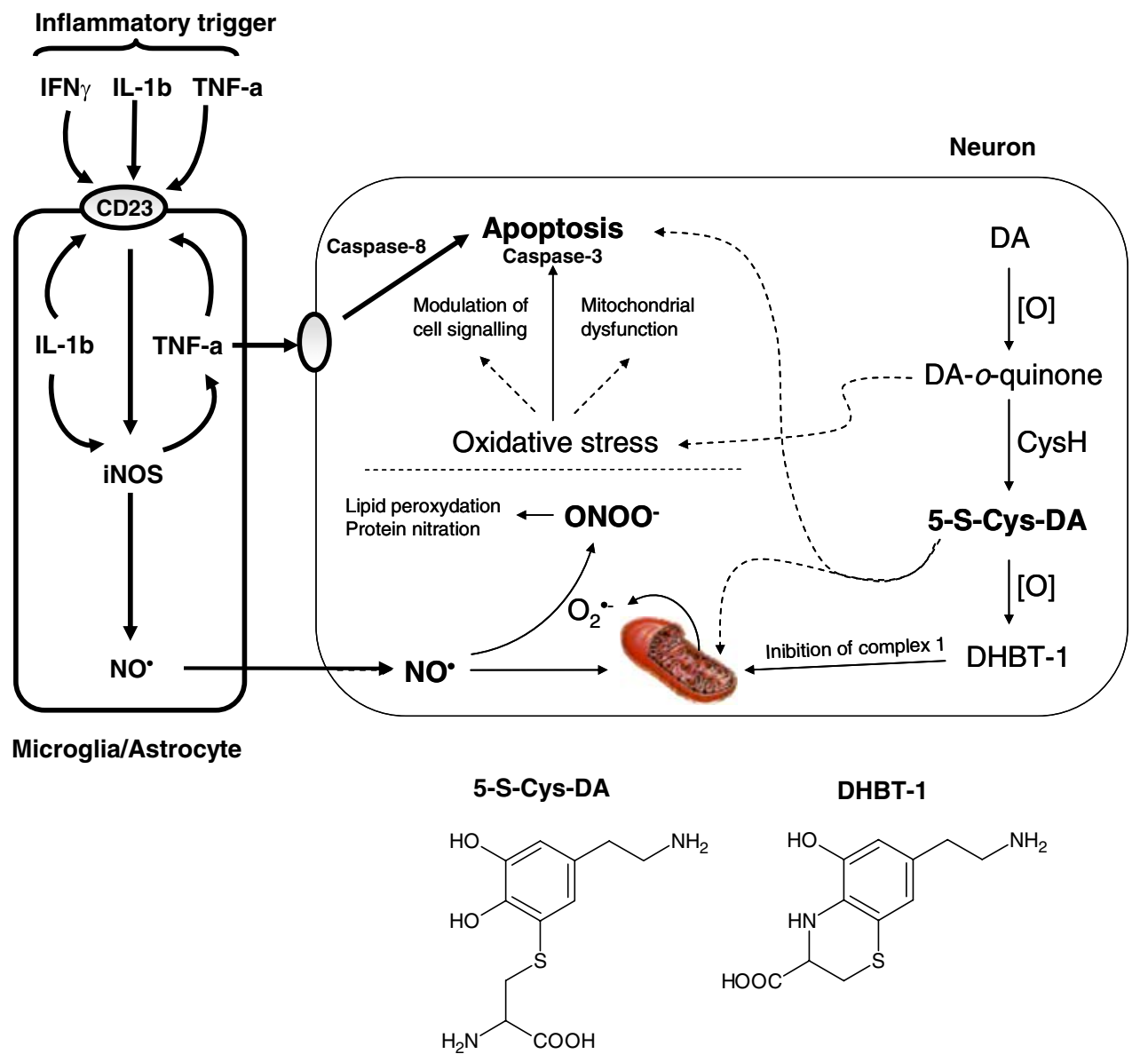


activation and delayed neuronal death [37, 111] (Fig. 2). Such adducts may be generated by reactive species [121] and have been observed to be been elevated in the human substantia nigra of patients who died of Parkinson's disease [108], suggesting that such species may be potential endogenous nigral toxins. However, 5-S-cysteinyldopamine-induced neuronal injury is counteracted by nanomolar concentrations of various flavonoids including pelargonidin, quercetin, hesperetin, caffeic acid, the $4^{\prime}-\mathrm{O}-$ Me derivatives of catechin and epicatechin [121]. Furthermore, in presence of the flavanol, (+)-catechin, tyrosinase-induced formation of 5-S-cysteinyl-dopamine was inhibited by a mechanism linked to the capacity of catechin to undergo tyrosinase-induced oxidation to yield cysteinyl-catechin adducts [123]. In contrast, the inhibition afforded by flavanones, such as hesperetin, was not accompanied with the formation of cysteinyl-hesperetin adducts, indicating that it may inhibit via direct interaction with tyrosinase [123].

Reactive oxygen and nitrogen species have also been proposed to play a role in the pathology of many neurodegenerative diseases [44] (Fig. 2). There is abundant evidence that flavonoids are effective in blocking this oxidant-induced neuronal injury, although their potential to do so is thought not to rely on direct radical or oxidant scavenging [98, 102, 110]. Instead, they are believed to act by modulating a number of protein kinase and lipid kinase signalling cascades, such as the PI3 kinase (PI3 K)/Akt, tyrosine kinase, protein kinase $\mathrm{C}(\mathrm{PKC})$ and mitogen-activated protein kinase (MAP kinase) signalling pathways [98, 130]. Inhibitory or stimulatory actions of these pathways are likely to profoundly affect neuronal function by altering the phosphorylation state of target molecules, leading to changes in caspase activity and/or by gene expression [130]. For example, flavonoids have been observed to block oxidative-induced neuronal damage by preventing the activation of caspase- 3 , providing evidence in support of their potent anti-apoptotic action [91, 92, 102]. The flavanols epicatechin and 3'-O-methylepicatechin also protect neurons against oxidative damage via a mechanism involving the suppression of JNK, and downstream partners, c-jun and pro-caspase-3 [91]. Flavanones, such as hesperetin and its metabolite, 5-nitrohesperetin, have been observed to inhibit oxidant-induced neuronal apoptosis via a mechanism involving the activation/phosphorylation of signalling proteins important in the pro-survival pathways [122]. Similarly, the flavone, baicalein, has been shown to significantly inhibit 6-hydroxydopamine-induced JNK activation and neuronal cell death and quercetin may suppress JNK activity and apoptosis induced by hydrogen peroxide [42, 124], 4-hydroxy-2-nonenal [119] and tumour necrosis factoralpha (TNF-alpha) [49].

\section{Inhibition of neuroinflammation}

Neuroinflammatory processes in the CNS are believed to play a crucial role in the development of neurodegenerative diseases such as Alzheimer's and Parkinson's disease [39] as well as with neuronal injury associated with stroke [137]. Glial cells (microglia and astrocytes) activation leads to the production of cytokines and other inflammatory mediators which may contribute to the apoptotic cell death of neurons observed in many neurodegenerative diseases. In particular, increases in cytokine production (interleukin-1 $\beta$, IL-1 $\beta$; tumor necrosis factor-alpha, TNF- $\alpha$ ) [50], inducible nitric oxide synthase (iNOS) and nitric oxide (NO), and increased NADPH oxidase activation [4] all contribute to glial-induced neuronal death (Fig. 2). These events are controlled by MAPK signalling which mediate both the transcriptional and post-transcriptional regulation of iNOS and cytokines in activated microglia and astrocytes [9, 69]. Whilst ibuprofen, a nonsteroidal anti-inflammatory drug, has been shown to delay the onset of neurodegenerative disorders, such as Parkinson disease [14], the majority of existing drug therapies for neurodegenerative disorders has failed to prevent the underlying degeneration of neurons. Consequently, there is a desire to develop alternative strategies capable of preventing the progressive neuronal loss resulting from neuroinflammation.

Flavonoid-rich blueberry extracts have been observed to inhibit NO, IL-1 $\beta$ and TNF- $\alpha$ production in activated microglia cells [53, 54], whilst the flavonol quercetin [17], the flavones wogonin and bacalein [55], the flavanols catechin and epigallocatechin gallate (EGCG) [62], and the isoflavone genistein [125] have all been shown to attenuate microglia and/or astrocyte mediated neuroinflammation via mechanisms that include inhibition of: (1) iNOS and cyclooxygenase (COX-2) expression, (2) NO production, (3) cytokine release, and (4) NADPH oxidase activation and subsequent reactive oxygen species generation, in astrocytes and microglia. Flavonoids may exert these effects via direct modulation of protein and lipid kinase signalling pathways $[98,105,130]$, for example via the inhibition of MAPK signalling cascades, such as p38 or ERK1/2 which regulate both iNOS and TNF- $\alpha$ expression in activated glial cells [9]. In this respect, fisetin inhibits p38 MAP kinase phosphorylation in LPS-stimulated BV-2 microglial cells [136] and the flavone luteolin inhibits IL-6 production in activated microglia via inhibition of the JNK signalling pathway. The effects of flavonoids on these kinases may influence downstream pro-inflammatory transcription factors important in iNOS transcription. One of these, nuclear factor-Kappa B (NF- $\kappa \mathrm{B}$ ), responds to p38 signalling and is involved in iNOS induction [8], suggesting that there is interplay between signalling pathways, transcription factors and cytokine 
production in determining the neuroinflammatory response in the CNS. However, flavonoids have also been shown to prevent transcription factor activation, with the flavonol quercetin able to suppress $\mathrm{NF}-\kappa \mathrm{B}$, signal transducer and activator of transcription-1 (STAT-1) and activating protein1 (AP-1) activation in LPS- and IFN- $\gamma$-activated microglial cells [17].

\section{Flavonoid-induced improvements in memory, learning and cognitive performance}

There is a growing interest in the potential of phytochemicals to improve memory, learning and general cognitive ability [105, 106]. A recent prospective study aimed at examining flavonoid intake in relation to cognitive function and decline, has provided strong evidence that dietary flavonoid intake is associated with better cognitive evolution, i.e. the preservation of cognitive performance with ageing [59]. In this PAQUID study (Personnes Agées QUID), a total of 1,640 subjects (aged 65 years or older) free from dementia at baseline and with reliable dietary assessment data were examined for their cognitive performance (Mini-Mental State Examination, Benton's Visual Retention Test, "Isaacs" Set Test) four times over a 10year-period. After adjustment for age, sex, and educational level, flavonoid intake was found to be associated with significantly better cognitive performance at baseline and with a significantly better evolution of the performance over time. In particular, subjects included in the two highest quartiles of flavonoid intake had better cognitive evolution than subjects in the lowest quartile and after 10 years follow-up, subjects with the lowest flavonoid intake had lost on average 2.1 points on the Mini-Mental State Examination, whereas subjects with the highest quartile had lost 1.2 points. Such data provides a strong indication that regular flavonoid consumption may have a positive effect on neuro-cognitive performance as we age.

There has been much interest in the neuro-cognitive effects of soy isoflavones (Fig. 1), primarily in post-menopausal women [10, 28, 57, 128]. Isoflavone supplementation has been observed to have a favourable effect on cognitive function [13], particularly verbal memory, in postmenopausal women [51] and a 6 and 12-week supplementation was observed to have a positive effect of frontal lobe function [27]. Furthermore, animal studies have also indicated that isoflavones are capable of improving cognitive function [58, $64,77]$. However, there is still uncertainty regarding their effects as some large intervention trials have reported that isoflavone supplementation does not lead to cognitive improvements [30]. The rationale behind the potential of isoflavones to exert positive effects on cognitive function is believed to lie primarily in their potential to mimic the actions and functions of oestrogens in the brain [10]. For example, postmenopausal women who undertake oestrogenreplacement therapy have a significantly lower risk for the onset of Alzheimer's disease than women who do not [38]. They may also be effective by affecting the synthesis of acetylcholine and neurotrophic factors such as brain-derived neurotrophic factor (BDNF) and nerve growth factor (NGF) in hippocampus and frontal cortex $[75,76]$.

There is also extensive evidence that berries, in particular blueberries, are effective at reversing age-related deficits in motor function and spatial working memory [5, $12,45,46,129]$. In addition to spatial memory, blueberry supplementation has been shown to improve 'object recognition memory' [34] and 'inhibitory fear conditioning learning' [5]. Blueberry appears to have a pronounced effect on short-term memory [82] and has also been shown to improve long-term reference memory following 8 weeks of supplementation. [12]. Tests using a radial arm maze have supported these findings and have provided further evidence for the efficacy of blueberries [129]. Indeed, these have shown that improvements in spatial memory may emerge within 3 weeks, the equivalent of about 3 years in humans. The beneficial effects of flavonoid-rich foods and beverages on psychomotor activity in older animals have also been reported $[95,96]$. In addition to those with berries, animal studies with tea [15] and pomegranate juice [36], or pure flavonols such as quercetin, rutin [80] or fisetin [66] have provided further evidence that dietary flavonoids are beneficial in reversing the course of neuronal and behavioural aging.

The flavonoid-rich plant extract, Ginkgo Biloba has also been shown to induce positive effects on memory, learning and concentration [19, 20, 25]. Ginkgo Biloba has a prominent effect on brain activity and short-term memory in animals and humans suffering from cognitive impairment $[43,93,131]$ and promotes spatial learning in aged rodents [40, 114, 126, 131]. Furthermore, Ginkgo Biloba promotes inhibitory avoidance conditioning in rats with high-dose intake leading to short-term, but not long-term, passive avoidance learning in senescent mice [114, 118]. However, the pharmacological mechanisms by which Ginkgo Biloba promotes cognitive effects are unclear, with its ability to elicit a reduction in levels of ROS [72, 73], to increase cerebral blood flow [33], to modulate brain fluidity [114], to interact with the muscarinic cholinergic system [18] and to protect the striatal dopaminergic system [81] all being suggested as possible mechanisms of brain action.

The effects of flavonoid-rich foods on neuro-cognitive function have been linked to the ability of flavonoids to interact with the cellular and molecular architecture responsible for memory and learning [105, 106], including those involved in long-term potentiation and synaptic plasticity [98] (Fig. 3). These effects are likely to lead to the 
Fig. 3 Signalling pathways underlying neuronal survival and cognitive performance. Flavonoids activate ERK-CREB pathway and the PI3 kinasemTOR cascade leading to changes in synaptic plasticity. They are also capable of influencing neurogenesis through the activation of PI3 kinase-Akt-eNOS

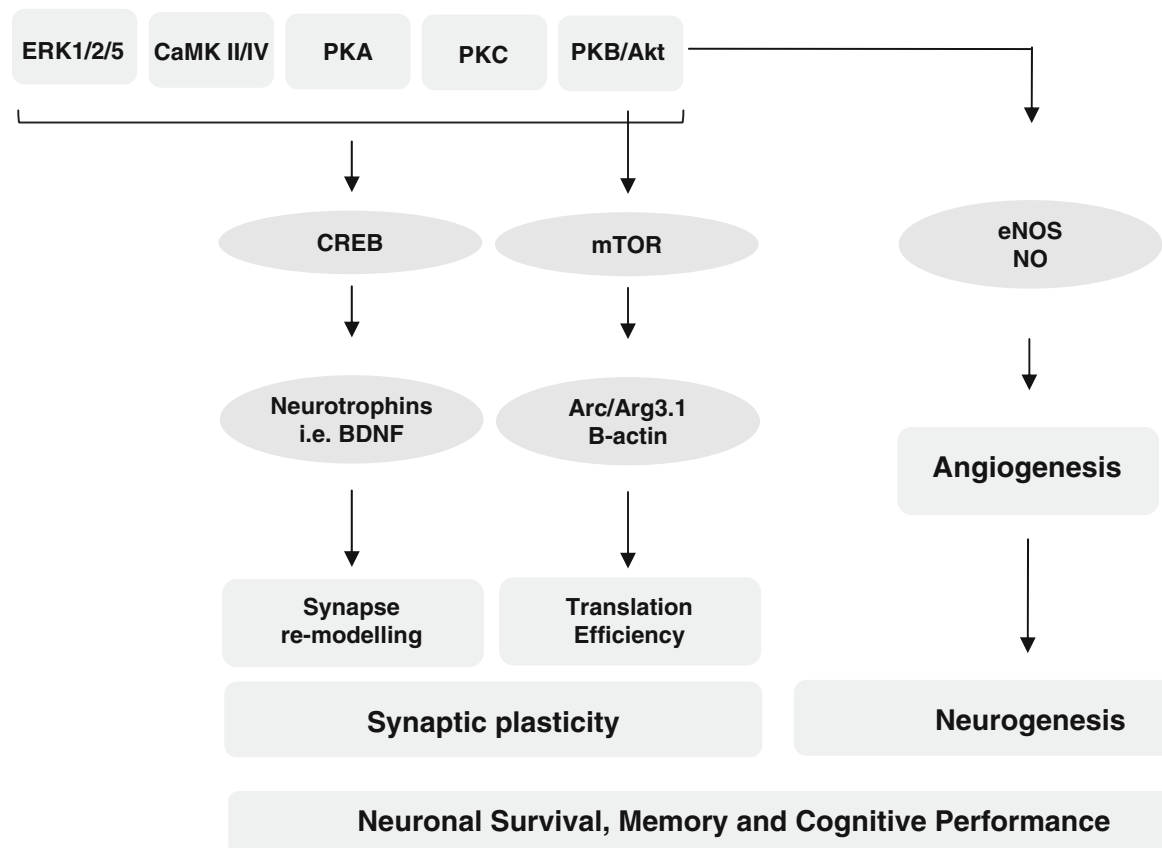

enhanced neuronal connection and communication and thus a greater capacity for memory acquisition, storage and retrieval [106]. For example, the flavanol (-)-epicatechin, especially in combination with exercise, has been observed to enhance the retention of rat spatial memory by a mechanism involving increased angiogenesis and neuronal spine density in the dentate gyrus of the hippocampus, and an upregulation of genes associated with learning in the hippocampus [120]. Fisetin, a flavonoid found in strawberries, has been shown to improve long-term potentiation and to enhance object recognition in mice by a mechanism dependent on the activation of ERK and CREB [66]. Similarly, the flavanol (-)-epicatechin induces both ERK1/2 and CREB activation in cortical neurons and subsequently increases CREB regulated gene expression [89], whilst nanomolar concentrations of quercetin are effective at enhancing CREB activation [101]. Blueberry-induced improvements in memory have been shown to be mediated by increases in the phosphorylation state of ERK1/2, rather than that of calcium calmodulin kinase (CaMKII and CaMKIV) or protein kinase A [129]. Other flavonoids have also been found to influence the ERK pathway, with the citrus flavanone hesperetin capable to activating ERK1/2 signalling in cortical neurons [122] and flavanols such as EGCG restoring both protein kinase $\mathrm{C}$ and ERK1/2 activities in 6-hydroxy dopamine toxicity and serum deprived neurons [61, 83].

\section{Cerebrovascular effects of flavonoids}

Dementia is a serious degenerative disease effecting predominantly elderly people with the two most common forms of this illness being Alzheimer's and vascular dementia. The factors affecting dementia are age, hypertension, arteriosclerosis, diabetes mellitus, smoking, atrial fibrillation and those with the ApoE4 genotype [11]. There is evidence to suggest that flavonoids may be capable of preventing many forms of cerebrovascular disease, including those associated with stroke and dementia [21, 23]. There is powerful evidence for the beneficial effects of flavonoids on endothelial function and peripheral blood flow [90] and these vascular effects are potentially significant as increased cerebrovascular function is known to facilitate adult neurogenesis in the hippocampus [32] (Fig. 3). Indeed, new hippocampal cells are clustered near blood vessels, proliferate in response to vascular growth factors and may influence memory [74]. As well as new neuronal growth, increases in neuronal spine density and morphology are considered vital for learning and memory [35]. Changes in spine density, morphology and motility have been shown to occur with paradigms that induce synaptic, as well as altered sensory experience, and lead to alterations in synaptic connectivity and strength between neuronal partners, affecting the efficacy of synaptic communication. These events are mediated at the cellular and molecular level and are strongly correlated with memory and learning.

Efficient cerebral blood flow is also vital for optimal brain function, with several studies indicating that there is a decrease in cerebral blood flow (CBF) in patients with dementia [71, 87]. Brain imaging techniques, such as 'functional magnetic resonance imaging' (fMRI) and 'trans-cranial Doppler ultrasound' (TCD) has shown that there is a correlation between $\mathrm{CBF}$ and cognitive function 
in humans [87]. For example, cerebral blood flow velocity is significantly lower in patients with Alzheimer disease and low CBF is also associated with incipient markers of dementia. In contrast, non demented subjects with higher CBF were less likely to develop dementia. Flavonoids have been shown to exert a positive effect on cerebral blood flow $(\mathrm{CBF})$ in humans [29, 31]. After consumption of a flavanolrich cocoa drink, the 'flow oxygenation level dependent' (BOLD)-fMRI showed an increase in blood flow in certain regions of the brain, along with a modification of the BOLD response to task switching. Furthermore, 'arterial spin-labelling sequence magnetic resonance imaging' (ASL-MRI) [127] also indicated that cocoa flavanols increase CBF up to a maximum of two hours after ingestion of the flavanol-rich drink. In support of these findings, an increase in cerebral blood flow through the middle cerebral artery has been reported after the consumption of flavanol-rich cocoa using TCD [29].

\section{Conclusion}

The neuroprotective actions of dietary flavonoids involve a number of effects within the brain, including a potential to protect neurons against injury induced by neurotoxins, an ability to suppress neuroinflammation, and the potential to promote memory, learning and cognitive function. This multiplicity of effects appears to be underpinned by two common processes. Firstly, they interact with important neuronal signalling cascades in the brain leading to an inhibition of apoptosis triggered by neurotoxic species and to a promotion of neuronal survival and differentiation. These include selective actions on a number of protein kinase and lipid kinase signalling cascades, most notably the PI3 K/Akt and MAP kinase pathways which regulate pro-survival transcription factors and gene expression (Fig. 3). It appears that the concentrations of flavonoids encountered in the brain may be sufficiently high to exert such pharmacological activity on receptors, kinases and transcription factors. Secondly, they are known to induce beneficial effects on the peripheral and cerebral vascular system, which lead to changes in cerebrovascular blood flow. Such changes are likely to induce angiogenesis, new nerve cell growth in the hippocampus and changes in neuronal morphology, all processes known to important in maintaining optimal neuronal function and neuro-cognitive performance (Fig. 3).

The consumption of flavonoid-rich foods, such as berries and cocoa, throughout life holds a potential to limit neurodegeneration and prevent or reverse age-dependent deteriorations cognitive performance. However, at present the precise temporal nature of the effects of flavonoids on these events is unclear. For example, it is presently unclear as to when one needs to begin consuming flavonoids in order to obtain maximum benefits. It is also unclear which flavonoids are most effective in inducing these changes. However, due to the intense interest in the development of drugs capable of enhancing brain function, flavonoids may represent important precursor molecules in the quest to develop of a new generation of brain enhancing drugs.

Acknowledgments The authors are funded by the Biotechnology and Biological Sciences Research Council (BB/F008953/1; BB/ C518222/1; BB/G005702/1) and the Medical Research Council (G0400278/NI02).

\section{References}

1. Aasmundstad TA, Morland J, Paulsen RE (1995) Distribution of morphine 6-glucuronide and morphine across the bloodbrain barrier in awake, freely moving rats investigated by in vivo microdialysis sampling. J Pharmacol Exp Ther 275:435441

2. Abbott NJ (2002) Astrocyte-endothelial interactions and bloodbrain barrier permeability. J Anat 200:629-638

3. Abd El Mohsen MM, Kuhnle G, Rechner AR et al (2002) Uptake and metabolism of epicatechin and its access to the brain after oral ingestion. Free Radic Biol Med 33:1693-1702

4. Bal-Price A, Matthias A, Brown GC (2002) Stimulation of the NADPH oxidase in activated rat microglia removes nitric oxide but induces peroxynitrite production. J Neurochem 80:73-80

5. Barros D, Amaral OB, Izquierdo I et al (2006) Behavioral and genoprotective effects of Vaccinium berries intake in mice. Pharmacol Biochem Behav 84:229-234

6. Barzilai A, Melamed E (2003) Molecular mechanisms of selective dopaminergic neuronal death in Parkinson's disease. Trends Mol Med 9:126-132

7. Bastianetto S, Zheng WH, Quirion R (2000) The Ginkgo biloba extract (EGb 761) protects and rescues hippocampal cells against nitric oxide-induced toxicity: involvement of its flavonoid constituents and protein kinase C. J Neurochem 74:22682277

8. Bhat NR, Feinstein DL, Shen Q et al (2002) p38 MAPK-mediated transcriptional activation of inducible nitric-oxide synthase in glial cells. Roles of nuclear factors, nuclear factor kappa B, cAMP response element-binding protein, CCAAT/enhancerbinding protein-beta, and activating transcription factor-2. J Biol Chem 277:29584-29592

9. Bhat NR, Zhang P, Lee JC et al (1998) Extracellular signalregulated kinase and p38 subgroups of mitogen-activated protein kinases regulate inducible nitric oxide synthase and tumor necrosis factor-alpha gene expression in endotoxin-stimulated primary glial cultures. J Neurosci 18:1633-1641

10. Birge SJ (1996) Is there a role for estrogen replacement therapy in the prevention and treatment of dementia? J Am Geriatr Soc 44:865-870

11. Breteler MM (2000) Vascular risk factors for Alzheimer's disease: an epidemiologic perspective. Neurobiol Aging 21:153160

12. Casadesus G, Shukitt-Hale B, Stellwagen HM et al (2004) Modulation of hippocampal plasticity and cognitive behavior by short-term blueberry supplementation in aged rats. Nutr Neurosci 7:309-316

13. Casini ML, Marelli G, Papaleo E et al (2006) Psychological assessment of the effects of treatment with phytoestrogens on 
postmenopausal women: a randomized, double-blind, crossover, placebo-controlled study. Fertil Steril 85:972-978

14. Casper D, Yaparpalvi U, Rempel N et al (2000) Ibuprofen protects dopaminergic neurons against glutamate toxicity in vitro. Neurosci Lett 289:201-204

15. Chan YC, Hosoda K, Tsai CJ et al (2006) Favorable effects of tea on reducing the cognitive deficits and brain morphological changes in senescence-accelerated mice. J Nutr Sci Vitaminol (Tokyo) 52:266-273

16. Checkoway H, Powers K, Smith-Weller T et al (2002) Parkinson's disease risks associated with cigarette smoking, alcohol consumption, and caffeine intake. Am J Epidemiol 155:732-738

17. Chen JC, Ho FM, Pei-Dawn LC et al (2005) Inhibition of iNOS gene expression by quercetin is mediated by the inhibition of IkappaB kinase, nuclear factor-kappa B and STAT1, and depends on heme oxygenase-1 induction in mouse BV-2 microglia. Eur J Pharmacol 521:9-20

18. Chopin P, Briley M (1992) Effects of four non-cholinergic cognitive enhancers in comparinson with tacrine and galanthamine on scopolamine-induced amnesia in rats. Psychopharmacology 106:26-30

19. Clostre F (1999) Gingko Biloba extract (EGb 761). State of knowledgement in the dawn of the year 2000. Ann Pharm Fr 57:IS8-IS88

20. Cohen-Salmon C, Venault P, Martin B et al (1997) Effects of Ginkgo biloba extract (EGb 761) on learning and possible actions on aging. J Physiol Paris 91:291-300

21. Commenges D, Scotet V, Renaud S et al (2000) Intake of flavonoids and risk of dementia. Eur J Epidemiol 16:357-363

22. da Silva EL, Piskula MK, Yamamoto N et al (1998) Quercetin metabolites inhibit copper ion-induced lipid peroxidation in rat plasma. FEBS Lett 430:405-408

23. Dai Q, Borenstein AR, Wu Y et al (2006) Fruit and vegetable juices and Alzheimer's disease: the Kame Project. Am J Med 119:751-759

24. Datla KP, Christidou M, Widmer WW et al (2001) Tissue distribution and neuroprotective effects of citrus flavonoid tangeretin in a rat model of Parkinson's disease. Neuroreport 12:3871-3875

25. Diamond BJ, Shiflett SC, Feiwel N et al (2000) Ginkgo biloba extract: mechanisms and clinical indications. Arch Phys Med Rehabil 81:668-678

26. El Mohsen MA, Marks J, Kuhnle G et al (2006) Absorption, tissue distribution and excretion of pelargonidin and its metabolites following oral administration to rats. Br J Nutr 95:51-58

27. File SE, Hartley DE, Elsabagh S et al (2005) Cognitive improvement after 6 weeks of soy supplements in postmenopausal women is limited to frontal lobe function. Menopause 12:193-201

28. File SE, Jarrett N, Fluck E et al (2001) Eating soya improves human memory. Psychopharmacology (Berl) 157:430-436

29. Fisher ND, Sorond FA, Hollenberg NK (2006) Cocoa flavanols and brain perfusion. J Cardiovasc Pharmacol 47(Suppl 2):S210 S214

30. Fournier LR, Ryan Borchers TA, Robison LM et al (2007) The effects of soy milk and isoflavone supplements on cognitive performance in healthy, postmenopausal women. J Nutr Health Aging 11:155-164

31. Francis ST, Head K, Morris PG et al (2006) The effect of flavanol-rich cocoa on the fMRI response to a cognitive task in healthy young people. J Cardiovasc Pharmacol 47(Suppl 2):S215-S220

32. Gage FH (2000) Mammalian neural stem cells. Science 287:1433-1438

33. Gajewski A (1999) Gingko Biloba and memory for a maze. Psychol Rep 84:481-484
34. Goyarzu P, Malin DH, Lau FC et al (2004) Blueberry supplemented diet: effects on object recognition memory and nuclear factor-kappa B levels in aged rats. Nutr Neurosci 7:75-83

35. Harris KM, Kater SB (1994) Dendritic spines: cellular specializations imparting both stability and flexibility to synaptic function. Annu Rev Neurosci 17:341-371

36. Hartman RE, Shah A, Fagan AM et al (2006) Pomegranate juice decreases amyloid load and improves behavior in a mouse model of Alzheimer's disease. Neurobiol Dis 24:506-515

37. Hastings TG (1995) Enzymatic oxidation of dopamine: the role of prostaglandin H synthase. J Neurochem 64:919-924

38. Henderson VW (2006) Estrogen-containing hormone therapy and Alzheimer's disease risk: understanding discrepant inferences from observational and experimental research. Neuroscience 138:1031-1039

39. Hirsch EC, Hunot S, Hartmann A (2005) Neuroinflammatory processes in Parkinson's disease. Parkinsonism Relat Disord 11(Suppl 1):S9-S15

40. Hoffman JR, Donato A, Robbins SJ (2004) Ginkgo biloba promotes short-term retention of spatial memory in rats. Pharmacol Biochem Behav 77:533-539

41. Inanami O, Watanabe Y, Syuto B et al (1998) Oral administration of (-)catechin protects against ischemia-reperfusioninduced neuronal death in the gerbil. Free Radic Res 29:359365

42. Ishikawa Y, Kitamura M (2000) Anti-apoptotic effect of quercetin: intervention in the JNK- and ERK-mediated apoptotic pathways. Kidney Int 58:1078-1087

43. Itil TM, Eralp E, Ahmed I et al (1998) The pharmacological effects of Gingko Biloba, a plant extract, on the brain of dementia patients in comparinson with tacrine. Psychopharmacology 34:391-396

44. Jellinger KA (2001) Cell death mechanisms in neurodegeneration. J Cell Mol Med 5:1-17

45. Joseph JA, Shukitt-Hale B, Denisova NA et al (1999) Reversals of age-related declines in neuronal signal transduction, cognitive, and motor behavioral deficits with blueberry, spinach, or strawberry dietary supplementation. J Neurosci 19:8114-8121

46. Joseph JA, Shukitt-Hale B, Denisova NA et al (1998) Long-term dietary strawberry, spinach, or vitamin E supplementation retards the onset of age-related neuronal signal-transduction and cognitive behavioral deficits. J Neurosci 18:8047-8055

47. Kalt W, Blumberg JB, McDonald JE et al (2008) Identification of anthocyanins in the liver, eye, and brain of blueberry-fed pigs. J Agric Food Chem 56:705-712

48. Kim H, Kim YS, Kim SY et al (2001) The plant flavonoid wogonin suppresses death of activated C6 rat glial cells by inhibiting nitric oxide production. Neurosci Lett 309:67-71

49. Kobuchi H, Roy S, Sen CK et al (1999) Quercetin inhibits inducible ICAM-1 expression in human endothelial cells through the JNK pathway. Am J Physiol 277:C403-C411

50. Kozuka N, Itofusa R, Kudo Y et al (2005) Lipopolysaccharide and proinflammatory cytokines require different astrocyte states to induce nitric oxide production. J Neurosci Res $82: 717-728$

51. Kritz-Silverstein D, Von MD, Barrett-Connor E et al (2003) Isoflavones and cognitive function in older women: the SOy and Postmenopausal Health In Aging (SOPHIA) Study. Menopause 10:196-202

52. Kroemer HK, Klotz U (1992) Glucuronidation of drugs. A reevaluation of the pharmacological significance of the conjugates and modulating factors. Clin Pharmacokinet 23:292-310

53. Lau FC, Bielinski DF, Joseph JA (2007) Inhibitory effects of blueberry extract on the production of inflammatory mediators in lipopolysaccharide-activated BV2 microglia. J Neurosci Res 85:1010-1017 
54. Lau FC, Shukitt-Hale B, Joseph JA (2007) Nutritional intervention in brain aging: reducing the effects of inflammation and oxidative stress. Subcell Biochem 42:299-318

55. Lee H, Kim YO, Kim H et al (2003) Flavonoid wogonin from medicinal herb is neuroprotective by inhibiting inflammatory activation of microglia. FASEB J 17:1943-1944

56. Lee S, Suh S, Kim S (2000) Protective effects of the green tea polyphenol (-)-epigallocatechin gallate against hippocampal neuronal damage after transient global ischemia in gerbils. Neurosci Lett 287:191-194

57. Lee YB, Lee HJ, Sohn HS (2005) Soy isoflavones and cognitive function. J Nutr Biochem 16:641-649

58. Lee YB, Lee HJ, Won MH et al (2004) Soy isoflavones improve spatial delayed matching-to-place performance and reduce cholinergic neuron loss in elderly male rats. J Nutr 134:18271831

59. Letenneur L, Proust-Lima C, Le GA et al (2007) Flavonoid intake and cognitive decline over a 10-year period. Am J Epidemiol 165:1364-1371

60. Levites Y, Weinreb O, Maor G et al (2001) Green tea polyphenol (-)-epigallocatechin-3-gallate prevents N-methyl-4phenyl-1, 2, 3, 6-tetrahydropyridine-induced dopaminergic neurodegeneration. J Neurochem 78:1073-1082

61. Levites Y, Youdim MB, Maor G et al (2002) Attenuation of 6hydroxydopamine (6-OHDA)-induced nuclear factor-kappaB (NF-kappaB) activation and cell death by tea extracts in neuronal cultures. Biochem Pharmacol 63:21-29

62. Li R, Huang YG, Fang D et al (2004) (-)-Epigallocatechin gallate inhibits lipopolysaccharide-induced microglial activation and protects against inflammation-mediated dopaminergic neuronal injury. J Neurosci Res 78:723-731

63. Lin JH, Yamazaki M (2003) Role of P-glycoprotein in pharmacokinetics: clinical implications. Clin Pharmacokinet 42:5998

64. Lund TD, West TW, Tian LY et al (2001) Visual spatial memory is enhanced in female rats (but inhibited in males) by dietary soy phytoestrogens. BMC Neurosci 2:20

65. Luo Y, Smith JV, Paramasivam V et al (2002) Inhibition of amyloid-beta aggregation and caspase- 3 activation by the Ginkgo biloba extract EGb761. Proc Natl Acad Sci USA 99:12197-12202

66. Maher P, Akaishi T, Abe K (2006) Flavonoid fisetin promotes ERK-dependent long-term potentiation and enhances memory. Proc Natl Acad Sci USA 103:16568-16573

67. Manach C, Scalbert A, Morand C et al (2004) Polyphenols: food sources and bioavailability. Am J Clin Nutr 79:727-747

68. Mandel S, Youdim MB (2004) Catechin polyphenols: neurodegeneration and neuroprotection in neurodegenerative diseases. Free Radic Biol Med 37:304-317

69. Marcus JS, Karackattu SL, Fleegal MA et al (2003) Cytokinestimulated inducible nitric oxide synthase expression in astroglia: role of Erk mitogen-activated protein kinase and NFkappaB. Glia 41:152-160

70. Miyake Y, Shimoi K, Kumazawa S et al (2000) Identification and antioxidant activity of flavonoid metabolites in plasma and urine of eriocitrin-treated rats. J Agric Food Chem 48:32173224

71. Nagahama Y, Nabatame H, Okina T et al (2003) Cerebral correlates of the progression rate of the cognitive decline in probable Alzheimer's disease. Eur Neurol 50:1-9

72. Oyama Y, Chikahisa L, Ueha T et al (1996) Ginkgo biloba extract protects brain neurons against oxidative stress induced by hydrogen peroxide. Brain Res 712:349-352

73. Oyama Y, Fuchs PA, Katayama N et al (1994) Myricetin and quercetin, the flavonoid constituents of Ginkgo biloba extract, greatly reduce oxidative metabolism in both resting and $\mathrm{Ca}(2+)$ loaded brain neurons. Brain Res 635:125-129

74. Palmer TD, Willhoite AR, Gage FH (2000) Vascular niche for adult hippocampal neurogenesis. J Comp Neurol 425:479-494

75. Pan Y, Anthony M, Clarkson TB (1999) Effect of estradiol and soy phytoestrogens on choline acetyltransferase and nerve growth factor mRNAs in the frontal cortex and hippocampus of female rats. Proc Soc Exp Biol Med 221:118-125

76. Pan Y, Anthony M, Clarkson TB (1999) Evidence for upregulation of brain-derived neurotrophic factor mRNA by soy phytoestrogens in the frontal cortex of retired breeder female rats. Neurosci Lett 261:17-20

77. Pan Y, Anthony M, Watson S et al (2000) Soy phytoestrogens improve radial arm maze performance in ovariectomized retired breeder rats and do not attenuate benefits of 17beta-estradiol treatment. Menopause 7:230-235

78. Passamonti S, Vrhovsek U, Vanzo A et al (2005) Fast access of some grape pigments to the brain. J Agric Food Chem 53:70297034

79. Peng HW, Cheng FC, Huang YT et al (1998) Determination of naringenin and its glucuronide conjugate in rat plasma and brain tissue by high-performance liquid chromatography. J Chromatogr B Biomed Sci Appl 714:369-374

80. Pu F, Mishima K, Irie K et al (2007) Neuroprotective effects of quercetin and rutin on spatial memory impairment in an 8-arm radial maze task and neuronal death induced by repeated cerebral ischemia in rats. J Pharmacol Sci 104:329-334

81. Ramassamy C, Clostre F, Christen Y et al (1990) Prevention by a Ginkgo Biloba extract (GBE 761) of the dopaminergic neurotoxicity of MPTP. J Pharm Pharmacol 42:785-789

82. Ramirez MR, Izquierdo I, s Raseira M et al (2005) Effect of lyophilised Vaccinium berries on memory, anxiety and locomotion in adult rats. Pharmacol Res 52:457-462

83. Reznichenko L, Amit T, Youdim MB et al (2005) Green tea polyphenol (-)-epigallocatechin-3-gallate induces neurorescue of long-term serum-deprived PC12 cells and promotes neurite outgrowth. J Neurochem 93:1157-1167

84. Rice-Evans C (1995) Plant polyphenols: free radical scavengers or chain-breaking antioxidants? Biochem Soc Symp 61:103-116

85. Rice-Evans C (2001) Flavonoid antioxidants. Curr Med Chem 8:797-807

86. Rice-Evans CA, Miller NJ, Paganga G (1996) Structure-antioxidant activity relationships of flavonoids and phenolic acids. Free Radic Biol Med 20:933-956

87. Ruitenberg A, den Heijer T, Bakker SL et al (2005) Cerebral hypoperfusion and clinical onset of dementia: the Rotterdam Study. Ann Neurol 57:789-794

88. Scheline RR (1999) Metabolism of Oxygen Heterocyclic Compounds. CRC Handbook of mammalian metabolism of plant compounds. CRC Press Inc., Boca Ranton, pp 243-95

89. Schroeter H, Bahia P, Spencer JP et al (2007) (-)Epicatechin stimulates ERK-dependent cyclic AMP response element activity and up-regulates GluR2 in cortical neurons. J Neurochem 101:1596-1606

90. Schroeter H, Heiss C, Balzer J et al (2006) (-)-Epicatechin mediates beneficial effects of flavanol-rich cocoa on vascular function in humans. Proc Natl Acad Sci USA 103:1024-1029

91. Schroeter H, Spencer JP, Rice-Evans C et al (2001) Flavonoids protect neurons from oxidized low-density-lipoprotein-induced apoptosis involving c-Jun N-terminal kinase (JNK), c-Jun and caspase-3. Biochem J 358:547-557

92. Schroeter H, Williams RJ, Matin R et al (2000) Phenolic antioxidants attenuate neuronal cell death following uptake of oxidized low-density lipoprotein. Free Radic Biol Med 29:1222-1233 
93. Shif O, Gillette K, Damkaoutis CM et al (2006) Effects of Ginkgo biloba administered after spatial learning on water maze and radial arm maze performance in young adult rats. Pharmacol Biochem Behav 84:17-25

94. Shirai M, Moon JH, Tsushida T et al (2001) Inhibitory effect of a quercetin metabolite, quercetin 3-O-beta-D-glucuronide, on lipid peroxidation in liposomal membranes. J Agric Food Chem 49:5602-5608

95. Shukitt-Hale B, Carey A, Simon L et al (2006) Effects of Concord grape juice on cognitive and motor deficits in aging. Nutrition 22:295-302

96. Shukitt-Hale B, Smith DE, Meydani M et al (1999) The effects of dietary antioxidants on psychomotor performance in aged mice. Exp Gerontol 34:797-808

97. Smith JV, Burdick AJ, Golik P et al (2002) Anti-apoptotic properties of Ginkgo biloba extract EGb 761 in differentiated PC12 cells. Cell Mol Biol (Noisy -le-grand) 48:699-707

98. Spencer JPE (2007) The interactions of flavonoids within neuronal signalling pathways. Gen Nutr 2:257-273

99. Spencer JPE, Chowrimootoo G, Choudhury R et al (1999) The small intestine can both absorb and glucuronidate luminal flavonoids. FEBS Lett 458:224-230

100. Spencer JPE, Kuhnle GG, Williams RJ et al (2003) Intracellular metabolism and bioactivity of quercetin and its in vivo metabolites. Biochem J 372:173-181

101. Spencer JPE, Rice-Evans C, Williams RJ (2003) Modulation of pro-survival Akt/protein kinase B and ERK1/2 signaling cascades by quercetin and its in vivo metabolites underlie their action on neuronal viability. J Biol Chem 278:34783-34793

102. Spencer JPE, Schroeter H, Crossthwaithe AJ et al (2001) Contrasting influences of glucuronidation and O-methylation of epicatechin on hydrogen peroxide-induced cell death in neurons and fibroblasts. Free Radic Biol Med 31:1139-1146

103. Spencer JPE, Schroeter H, Rechner AR et al (2001) Bioavailability of flavan-3-ols and procyanidins: gastrointestinal tract influences and their relevance to bioactive forms in vivo. Antioxid Redox Signal 3:1023-1039

104. Spencer JPE (2003) Metabolism of tea flavonoids in the gastrointestinal tract. J Nutr 133:3255S-3261S

105. Spencer JPE (2008) Flavonoids: modulators of brain function? Br J Nutr 99(E Suppl 1):ES60-ES77

106. Spencer JPE (2008) Food for thought: the role of dietary flavonoids in enhancing human memory, learning and neurocognitive performance. Proc Nutr Soc 67:238-252

107. Spencer JPE, Abd El Mohsen MM, Minihane AM et al (2007) Biomarkers of the intake of dietary polyphenols: strengths, limitations and application in nutrition research. Br J Nutr:1-11

108. Spencer JPE, Jenner P, Daniel SE et al (1998) Conjugates of catecholamines with cysteine and GSH in Parkinson's disease: possible mechanisms of formation involving reactive oxygen species. J Neurochem 71:2112-2122

109. Spencer JPE, Jenner P, Halliwell B (1995) Superoxide-dependent depletion of reduced glutathione by L-DOPA and dopamine. Relevance to Parkinson's disease. Neuroreport 6:1480-1484

110. Spencer JPE, Schroeter H, Kuhnle G et al (2001) Epicatechin and its in vivo metabolite, $3^{\prime}$-O-methyl epicatechin, protect human fibroblasts from oxidative-stress-induced cell death involving caspase-3 activation. Biochem J 354:493-500

111. Spencer JPE, Whiteman M, Jenner P et al (2002) 5-s-Cysteinylconjugates of catecholamines induce cell damage, extensive DNA base modification and increases in caspase- 3 activity in neurons. J Neurochem 81:122-129

112. Sperker B, Backman JT, Kroemer HK (1997) The role of betaglucuronidase in drug disposition and drug targeting in humans. Clin Pharmacokinet 33:18-31
113. Spires TL, Hannan AJ (2005) Nature, nurture, neurology: geneenvironment interactions in neurodegenerative disease. FEBS Anniversary Prize Lecture delivered on 27 June 2004 at the 29th FEBS Congress in Warsaw. FEBS J 272:2347-2361

114. Stoll S, Scheuer K, Pohl O et al (1996) Ginkgo biloba extract (EGb 761) independently improves changes in passive avoidance learning and brain membrane fluidity in the aging mouse. Pharmacopsychiatry 29:144-149

115. Suganuma M, Okabe S, Oniyama M et al (1998) Wide distribution of [H-3](-)-epigallocatechin gallate, a cancer preventive tea polyphenol, in mouse tissue. Carcinogenesis 19:1771-1776

116. Talavera S, Felgines C, Texier O et al (2005) Anthocyanin metabolism in rats and their distribution to digestive area, kidney, and brain. J Agric Food Chem 53:3902-3908

117. Terao J, Yamaguchi S, Shirai M et al (2001) Protection by quercetin and quercetin 3-O-beta-D-glucuronide of peroxynitrite-induced antioxidant consumption in human plasma lowdensity lipoprotein. Free Radic Res 35:925-931

118. Topic B, Hasenohrl RU, Hacker R et al (2002) Enhanced conditioned inhibitory avoidance by a combined extract of Zingiber officinale and Ginkgo biloba. Phytother Res 16:312-315

119. Uchida K, Shiraishi M, Naito Y et al (1999) Activation of stress signaling pathways by the end product of lipid peroxidation. 4-hydroxy-2-nonenal is a potential inducer of intracellular peroxide production. J Biol Chem 274:2234-2242

120. van Praag H, Lucero MJ, Yeo GW et al (2007) Plant-derived flavanol (-)epicatechin enhances angiogenesis and retention of spatial memory in mice. J Neurosci 27:5869-5878

121. Vauzour D, Ravaioli G, VafeiAdou K et al (2008) Peroxynitrite induced formation of the neurotoxins 5-S-cysteinyl-dopamine and DHBT-1: implications for Parkinson's disease and protection by polyphenols. Arch Biochem Biophys 476:145-151

122. Vauzour D, VafeiAdou K, Rice-Evans C et al (2007) Activation of pro-survival Akt and ERK1/2 signalling pathways underlie the anti-apoptotic effects of flavanones in cortical neurons. J Neurochem 103:1355-1367

123. Vauzour D, VafeiAdou K, Spencer JP (2007) Inhibition of the formation of the neurotoxin 5-S-cysteinyl-dopamine by polyphenols. Biochem Biophys Res Commun 362:340-346

124. Wang L, Matsushita K, Araki I et al (2002) Inhibition of c-Jun $\mathrm{N}$-terminal kinase ameliorates apoptosis induced by hydrogen peroxide in the kidney tubule epithelial cells (NRK-52E). Nephron 91:142-147

125. Wang X, Chen S, Ma G et al (2005) Genistein protects dopaminergic neurons by inhibiting microglial activation. Neuroreport 16:267-270

126. Wang Y, Wang L, Wu J et al (2006) The in vivo synaptic plasticity mechanism of EGb 761-induced enhancement of spatial learning and memory in aged rats. $\mathrm{Br} \mathrm{J}$ Pharmacol 148:147-153

127. Wang Z, Fernandez-Seara M, Alsop DC et al (2008) Assessment of functional development in normal infant brain using arterial spin labeled perfusion MRI. Neuroimage 39:973-978

128. White LR, Petrovitch H, Ross GW et al (2000) Brain aging and midlife tofu consumption. J Am Coll Nutr 19:242-255

129. Williams CM, El Mohsen MA, Vauzour D et al (2008) Blueberry-induced changes in spatial working memory correlate with changes in hippocampal CREB phosphorylation and brainderived neurotrophic factor (BDNF) levels. Free Radic Biol Med 45:295-305

130. Williams RJ, Spencer JP, Rice-Evans C (2004) Flavonoids: antioxidants or signalling molecules? Free Radic Biol Med $36: 838-849$

131. Winter JC (1998) The effects of an extract of Ginkgo biloba, EGb 761, on cognitive behavior and longevity in the rat. Physiol Behav 63:425-433 
132. Yamamoto N, Moon JH, Tsushida $\mathrm{T}$ et al (1999) Inhibitory effect of quercetin metabolites and their related derivatives on copper ion-induced lipid peroxidation in human low-density lipoprotein. Arch Biochem Biophys 372:347-354

133. Youdim KA, Dobbie MS, Kuhnle G et al (2003) Interaction between flavonoids and the blood-brain barrier: in vitro studies. J Neurochem 85:180-192

134. Youdim KA, Joseph JA (2001) A possible emerging role of phytochemicals in improving age-related neurological dysfunctions: a multiplicity of effects. Free Radic Biol Med 30:583-594
135. Youdim KA, Qaiser MZ, Begley DJ et al (2004) Flavonoid permeability across an in situ model of the blood-brain barrier. Free Radic Biol Med 36:592-604

136. Zheng LT, Ock J, Kwon BM et al (2008) Suppressive effects of flavonoid fisetin on lipopolysaccharide-induced microglial activation and neurotoxicity. Int Immunopharmacol 8:484-494

137. Zheng Z, Lee JE, Yenari MA (2003) Stroke: molecular mechanisms and potential targets for treatment. Curr Mol Med 3:361372 